\section{International Scientific \\ SOI: $\underline{1.1 / \text { TAS }}$ DOI: $10.15863 /$ AS Theoretical \& Applied Science}

Helen M. Subchinskaya

Assistant of the Department of Management, Odessa National Polytechnic Institute, Ukraine helen_1983@list.ru

p-ISSN: 2308-4944 (print) e-ISSN: 2409-0085 (online)

Tatiana I. Postovaya Student,

Year: 2015 Issue: 05 Volume: 25

Published: $30.05 .2015 \quad$ http://T-Science.org

SECTION 31. Economic research, finance, innovation, risk management.
Odessa National Polytechnic Institute, Ukraine

Victoria V. Nazarova

Student,

Odessa National Polytechnic Institute, Ukraine tori601@ukr.net

\title{
THE STRATEGY OF USING HUMAN POTENTIAL IN THE COUNTRY'S ECONOMY
}

Abstract: The article reviewed by the effective use of human potential by achieving excellence and increasing value of the personal factor which is a the main value of economic development at both the regional and national level.

Key words: strategy, human resources, human potential, regional economy, the national economy.

Language: Russian

Citation: Subchinskaya HM, Postovaya TI, Nazarova VV (2015) THE STRATEGY OF USING HUMAN POTENTIAL IN THE COUNTRY'S ECONOMY. ISJ Theoretical \& Applied Science 05 (25): 119-122.

Soi: http://s-o-i.org/1.1/TAS*05(25)21 Doi: crossef http://dx.doi.org/10.15863/TAS.2015.05.25.21

\section{УДК 331.5.024.54}

\section{СТРАТЕГИЯ ИСПОЛЬЗОВАНИЯ ЧЕЛОВЕЧЕСКОГО ПОТЕНЦИАЛА В ЭКОНОМИКЕ СТРАНЫ}

Аннотация: В данной статье расмотрено эффективное использование человеческого потенциала путем достижения высокого профессионализма и усиления значимости личностного фактора, что является главной ценностью экономического развития как на региональном так и на национальном уровне.

Ключевые слова: стратегия, человеческие ресурсы, человеческий потенциал, региональная экономика, нацииональная экономика.

Целесообразность и актуальность данного исследования, лежит в перспективе формирования, использования, разработки и реализации стратегии эффективного использования человеческого потенциала страны, что приведет к положительным изменениям и продуктивным сдвигам в экономических (ВВП на душу населения, уровень занятости и безработицы, заработная плата), демографических (численность населения страны, экономически активное население, половозрастная структура, средняя продолжительность жизни) и социальных (уровень грамотности и образования населения, занятых и безработных) показателях.

Категория «человеческий потенциал» и его основные составляющие были расмотренны в работах таких ученых: А.Б. Докторовича, Н.В. Зубаревич ,Н.М. Римашевской, С. Ананда, С.А. Айвазяна, Р.И. Капелюшникова и др., а взаимосвязь развития человеческого потенциала и экономического роста как в национальном, так и региональном аспекте, лежит в основе трудов Д. Асемоглу, Р.Дж. Барро, Г.С. Беккера, Р. Бенабу, Р. Лукаса, Х. Сала-и-Мартина, Т.У. Шульца и др.

А. Сен считал: «что развитие человеческого потенциала подразумевает развитие человеческих способностей, расширение возможностей их применения в жизни и тем самым возможностей самореализации человека» [2].

Пристальное внимание экономистов к воспроизводству человеческих ресурсов объясняется усилением значения личного

фактора в современной воспроизводственной картине экономического мира.

Украина вступает в новый этап развития страны на основе структурных преобразований, модернизации и перехода к инновационной экономике. Поэтому в сложившихся условиях рыночной экономики для успешной и устойчивой экономики страны нужно разрабатывать стратегию использования человеческого 
потенциала - реализации возможностей и обеспечение безопасности жизни населения, его политических и гражданских прав, свободы личности, достижение высоких стандартов качества жизни на долгосрочный период.

В осуществлении происходящих процессов и намечаемых стратегических проектов значительно возрастает роль человеческого фактора. В этих условиях проблема разработки стратегии использования важнейшего человеческкого ресурса производства и экономического роста страны приобретает первостепенное значение. При этом формирование конкурентоспособного квалифицированного кадрового потенциала предприятий для экономики страны выдвигается как важнейшая государственная задача.

На сегодняшний день неэффективное использование человеческих ресурсов сказывается на темпах роста производства и конкурентоспособности экономики страны, определяя ее национальные интересы. Поэтому рациональное использование человеческих ресурсов в необходимом для экономики объеме является одной из приоритетных задач, участвующих в реализации национальных проектов, основных направлений демографической политики, развитии гибкого рынка труда, модернизации системы образования и здравоохранения [1].

Данное исследование в современной интерпритации, должно исходить из долгосрочной стратегии эффективного использования человеческого потенциала в процессе ее становления и формирования в соответствии с международными стандартами.

В последнее время человеческое развитие все больше рассматривается с точки зрения, создания благоприятной среды жизни человека и его трудовой деятельности, имея в виду экономически безопасные условия труда, его охраны им тема самым уменьшение производственного травматизма. Также большое внимание международными организациями и научной общественностью уделяется проблеме качества жизни с определением социальных стандартов, сопоставимых с принятыми в развитых странах [3].

Стратегия эффективного использования человеческого потенциала должна состоять из : общей долгосрочной стратегии комплексного развития потенциалов страны переходя к новому качеству экономического роста и инновационной экономики;

- критериев оценки и показателей измерения человеческого потенциала;

- качественной и эффективной реализация даной стратегии человеческого потенциала в условиях формирования новой модели занятости и подготовки квалифицированных кадров в экономике страны.

Достижение экономического роста автоматически влечет за собой прогресс в развитии человека и всего общества. Однако в конечном итоге формула "экономический рост" = "развитие человеческого потенциала" не оправдала себя и выразилась в нарастании социально-политической нестабильности и бедности населения.

Программы развития ООН (ПРООН), которая ставит в центр общественного прогресса и рассматривает экономический рост скорее как средство, нежели как конечную цель развития человеческого потенциала.

В отчетах ПРООН о развитии человеческого потенциала Украина в 2009 г. занимала 89 место, а в 2014 г. - 83 место, это говорит о том что были улучшены показателей человеческого развития: средней продолжительности жизни, грамотности взрослого населения, совокупного коэффициента обучающихся в учебных заведениях всех ступеней в возрасте от 5 до 24 лет и величины произведенного в стране ВВП на душу населения, измеряемого в долларах США с учетом паритета покупательской способности национальной валюты $[4,5]$.

На современном этапе в контексте перехода к новому качеству экономического роста первостепенное значение приобретает развитие человеческого потенциала путем достижения высокого профессионализма в результате целенаправленной профессиональной подготовки с использованием новейших информационных и телекоммуникационных технологий. Такая подготовка позволит повысить конкурентоспособность и эффективную реализацию нового качества человеческого потенциала. Непрерывное обучение позволит работнику приобрести компетентность, квалификацию, потенциал к трудоустройству [3].

Человеческий потенциал стоит на таких трех китах как получить доступ к средствам существования, обеспечивающим достойный уровень жизни; приобрести, расширить и обновить знания; прожить долгую и здоровую жизнь.

Стратегия эффективного использования человеческого потенциала должна быть направлена на формирование новой модели занятости, основанной на трудоустройстве незанятого населения и снижении безработицы путем создания новых рабочих мест в результате структурных преобразований во всех областях экономики, успешного осуществления инновационных проектов. В то же время новые рабочие места должны быть востребованы в условиях дефицита квалифицированных специалистов и профессиональных рабочих 
кадров как на внутреннем так и на внешнем рынках страны.

Эффективное использование человеческого потенциала зависит от устойчивого развития экономики страны. Только благодаря этому возможно обеспечить достижение главной цели долгосрочной стратегии - благосостояние общества и новое качество жизни людей, что в свою очередь создает основу долголетия, образованности и достойного уровня жизни людей.

Теоретические построения процессов воспроизводства человека (работника, личного фактора, субъективного фактора, человеческого pecyрса, человеческого потенциала) и воспроизводства его способности к созидательной деятельности (прежде всего, трудовой) встраивались в общие воспроизводственные теории, создаваемые экономистами [6]. Большинство теорий воспроизводства, отражающих формирование и развитие человеческих ресурсов, сформировались под воздействием эволюции западной экономической мысли, идейномировоззренческие основания которой лежат в сциентической установке (традиции) обществознания.

Понятие «человеческий потенциал» подчеркивает не только новую роль человека в инновационной экономике, но сложные процессы интеграции материального и духовного производства в национальной экономике.

В виду устойчивых национальных различий в стоимости ресурсов, прежде всего, интеллектуально-творческих, предприниматели повышают свою конкурентоспособность посредством концентрации привлекаемых ресурсов вокруг стратегического ядра бизнеса. При этом различие в стоимости, например, интеллектуального ресурса в области ИТтехнологий оценивает по уровню заработных плат как 5,1 для оффшорных и локальных сотрудников[7, с.15.].

Стратегической целью государственной политики на рынке труда является обеспечение свободно избранной, продуктивной занятости и создание условий для более рационального использования трудового потенциала общества в соответствии с профессиональными возможностями каждого человека. Повышение эффективности человеческого потенциала страны должно сопровождаться сокращением избыточной занятости на производстве и перераспределением рабочей силы в альтернативные сферы деятельности. Основной целью государственной политики в этот период станет реализация системы мер по достижению эффективной занятости, отвечающей потребностям экономики.
Политика занятости населения в регионах и стране вцелом должна быть направлена на достижение наиболее полной сбалансированности спроса и предложения рабочей силы, повышение качества и конкурентоспособности трудового потенциала страны [8].

Человеческий потенциал является основным фактором, определяющим возможность получения синергетического эффекта. В свою очередь эффективное воспроизводство человеческого потенциала требует планомерного долгосрочного воздействия на его системообразующие составляющие, позволяющие целенаправленно изменять уровень активизации человеческого потенциала [9].

Для эффективного и стабильного функционирования экономики страны необходимо создать среду воспроизводства человеческого потенциала, что позволило бы своэвременно адаптироваться к любым изменениям, переориентировать при этом пути достижения главных стратегических целей.

Еще Ф. Тейлор обратил внимание на человеческий потенциал в процессе производства и доказал его значимость. Он положил начало многочисленным экспериментам по исследованию роли человека на производстве и научной организации труда.

Человеческим ресурсам свойственна гибкость, приспособляемость и обучаемость. Только человек может успешно подстраиваться под изменения окружающей среды, меняя свое поведение, но не меняясь сам как физический объект. Поэтому повышение квалификации становится ключевым инструментом, с помощью которого работники развиваются вместе с развитием науки и техники, совершенствованием технологий.

Анализ развития человеческого потенциала, основанный на учете трансакционных издержек, его взаимосвязи с социальным капиталом (социальным потенциалом), полнотой социального контракта, во многом определяющим процессы развития человеческого потенциала и использования человеческого капитала.

В отличие от человеческого потенциала,человеческий капитал вовлечен в процесс производства и характеризуется размером накопленных инвестиций, в том числе, вложенных до начала использования капитала, а также определенной величиной отдачи от инвестиций.

Развитие человеческого потенциала рассматривается как основа достижения устойчивого экономического роста в программных документах $\mathrm{OOH}$, причем экономический рост выступает не самоцелью, а 
средством их обеспечения [10]. Развитие человеческого потенциала чаще рассматривается как объект управления, нежели как экономическая категория, как цель и критерии общественного социально - экономического развития [11].

Человеческий капитал рассматривается как производственный ресурс, с точки зрения отдачи для производства, цена и доступность которого определяет его качество и количество в производстве, выбор технологии производства, вида деятельности, а процессы развития человеческого потенциала остаются за пределами анализа. Целевой функцией может выступать как максимизация функции общественного благосостояния, так и максимизация производственных результатов.

Для обоснования эффективной государственной политики развития человеческого потенциала важно выделение влияния северных факторов на экономическое и социальное развитие при элиминировании таких региональных проблем как периферийность территории, различие в темпах роста старопромышленных и развивающихся регионов, традиционно-отсталых и индустриально развитых регионов.

Развитие человеческого потенциала является главной ценностью экономического развития как на региональном так и на национальном уровне. Так как при сильной конкуренции, когда каждое предприятия одно за одним внедряет все более новые, инновационные технологии. Одним из конкурентных преимуществ является человеческий потенциал. Именно этим фактором может воспользоваться предприятием, поэтому нужно работать над развитием персонала, «выращивая» специально для предприятия специалистов которые станут базой эффективного использования человеческого потенциала как внешней (национальной) так и внутренней экономики страны.

\section{References:}

1. Nabiullina ES (2008) Prioritety deyatel'nosti na 2008 i srednesrochnuyu perspektivu/ E.S. Nabiullina // Ekonomist. - Moscow, 2008. №4. - pp.3-18.

2. Sen A (1989) Development as Capabilities Expansion // Journal of Development Planning - 19.- 1989.- pp. 42.

3. Mel'dakhanova M (2013) Strategiya effektivnogo ispol'zovaniya novogo kachestva chelovecheskogo potentsiala respubliki na srednesrochnuyu i dolgosrochnuyu perspektivu/Doklad VI-go Astaninskogo ekonomicheskogo foruma «Obespechenie sbalansirovannogo ekonomicheskogo rosta V formate G-Global», prokhodivshego 22-24 May 2013 Astana. Available: http://www.gosbook.ru/node/80758 (Accessed: 13.05.2015).

4. Shimov V (2003) Chelovecheskiy potentsial Belarusi: ekonomicheskie vyzovy i sotsial'nye otvety.

Available: http://un.by/print/ru/undp/nhdr/2003/shimov/59 b7b3ff2ddad.html (Accessed: 13.05.2015).

5. (2015) Razvitie chelovecheskogo potentsiala. Available:

http://www.undp.ru/index.php?iso=RU\&lid=2 \&pid=259 (Accessed: 13.05.2015).

6. Avtonomov VS (1998) Model' cheloveka V ekonomicheskoy nauke. SPb., 1998. - 230 p.

7. Yordon E (2006) Konkurentsiya v global'noy gonke za proizvoditel'nost'yu / E. Yordon. Moscow: Lori, 2006. - 367 p.
8. (2004) Natsional'naya strategiya ustoychivogo sotsial'no,ekonomicheskogo razvi,tiya Respubliki Belarus' na period do 2020 g./ Natsional'naya komissiya po ustoychivomu razvitiyu Resp. Belarus'; Redkollegiya: Ya.M. Aleksandrovich i dr. - Minsk: Yuni,pak., 2004. -200 p.

9. Gibadatova GR (2011) Osobennosti vosproizvodstva chelovecheskogo potentsiala na mikrourovne. Stat'ya opublikovana v zhurnale «Rossiyskoe predprinimatel'stvo», 2011. - № 5. - Vyp. 1 (183). - pp. 102-106.

10. (2010) Human Development Report 2010 (20th Anniversary Edition). The Real Wealth of Nations: Pathways to Human Development Available:

http://hdr.undp.org/en/reports/global/hdr2010/c hapters/en/ (Accessed: 13.05.2015).

11. (2008) O Kontseptsii dolgosrochnogo sotsial'no - ekonomicheskogo razvitiya Rossiyskoy Federatsii na period do 2020 goda Rasporyazhenie Pravitel'stva Rossiyskoy Federatsii № 1662-r ot 17.11.2008 .

12. Stanislavovna KE (2012) Razvitie chelovecheskogo potentsiala Rossiyskogo Severa. Dissertatsiya na soiskanie uchenoy stepeni doktora ekonomicheskikh naukpo spetsial'nosti 08.00.05 - Ekonomika i upravlenie narodnym khozyaystvom: ekonomika truda. Moscow - 2012. - 256 p. 